\title{
Serum total prostate-specific antigen values in men with symptomatic prostate enlargement in Nigeria: role in clinical decision-making
}

This article was published in the following Dove Press journal:

Clinical Interventions in Aging

30 December 2014

Number of times this article has been viewed

\author{
Ikenna I Nnabugwu ${ }^{1,2}$ \\ Fred O Ugwumba' \\ Oghenekaro A Enivwenae ${ }^{2}$ \\ Emeka I Udeh' \\ Chris O Otene ${ }^{2}$ \\ Chinwe A Nnabugwu ${ }^{3}$ \\ 'Urology Unit, Department of Surgery, \\ College of Medicine, University \\ of Nigeria, Nsukka, ${ }^{2}$ Urology Unit, \\ Department of Surgery, ${ }^{3}$ Department \\ of Medical Laboratory Services, \\ Federal Medical Centre, Asaba, Nigeria
}

Background: Prostatic enlargement is a common cause of bladder outlet obstruction in men in Nigeria. Malignant enlargements must be differentiated from benign enlargements for adequate treatment of each patient. High serum total prostate-specific antigen (tPSA) levels suggest malignancy, but some of the biopsies done due to a serum tPSA value $>4 \mathrm{ng} / \mathrm{mL}$ would be negative for malignancy because of the low specificity of tPSA for prostate cancer. This study aims to compare the histologic findings of all prostate specimens obtained from core needle biopsy, open simple prostatectomy, and transurethral resection of the prostate with the respective serum tPSA values in an attempt to decipher the role of serum tPSA in the management of these patients.

Methods: The case notes of patients attended to from April 2009 to March 2012 were analyzed. Essentially, the age of the patient, findings on digital rectal examination, abdominopelvic ultrasonography report on the prostate, serum tPSA, and histology reports from biopsy or prostatectomy specimens as indicated were extracted for analysis.

Results: The relationship between age, findings on digital rectal examination, serum tPSA, abdominopelvic ultrasonography report, and histology are compared. A statistically significant relationship existed between a malignant histology and age 65 years and older, suspicious findings on digital rectal examination, suspicious ultrasonography findings, and serum tPSA $>10 \mathrm{ng} / \mathrm{mL}$, but not tPSA $>4 \mathrm{ng} / \mathrm{mL}$.

Conclusion: In Nigerian patients with symptomatic prostate enlargement, serum tPSA should be seen as a continuum with increasing risk of prostate malignancy.

Keywords: serum total prostate-specific antigen, symptomatic prostate enlargement, prostate histology

\section{Introduction}

Prostatic enlargement is a common cause of bladder outlet obstruction among men in Nigeria. The enlargement usually leads to lower urinary tract symptoms, ${ }^{1}$ irrespective of whether it is benign or malignant. With wide acceptance of serum prostate-specific antigen (PSA) estimation, ${ }^{2}$ the ability to differentiate malignant from benign prostatic enlargement with or without symptoms before instituting definitive treatment has increased. ${ }^{3}$ However, an entirely new range of challenges have been encountered as a result of the poor sensitivity of serum total PSA (tPSA). ${ }^{3-5}$ The need to carry out prostate biopsy to confirm malignant prostate enlargement in cases of elevated serum tPSA comes to the fore. ${ }^{6}$ Some of these prostate biopsies will be negative for malignant cells or identify low-volume, low-grade adenocarcinoma of uncertain clinical significance. ${ }^{7,8}$ The sensitivity of serum tPSA in detecting prostate cancer has been put at $25 \%$ in screening programs ${ }^{8}$ and as high as $99.6 \%$ in patients with symptoms. ${ }^{9}$
Correspondence: Ikenna I Nnabugwu Urology Unit, Department of Surgery, College of Medicine, University of

Nigeria, Enugu Campus PMB 01129

Enugu, Nigeria

Email iinnabugwu@yahoo.com 
In Nigeria, a serum tPSA value $>4.0 \mathrm{ng} / \mathrm{mL}$ has been widely accepted as an indication to exclude adenocarcinoma of the prostate through biopsy of the prostate, ${ }^{10}$ a cut-off value adopted from studies done mostly outside Nigeria. ${ }^{11-13}$

Serum tPSA varies with body mass index, intravascular volume, prostate volume, benign and malignant diseases of the prostate. As a result, some studies have applied serum tPSA values of $3.0 \mathrm{ng} / \mathrm{mL}$ instead of $>4.0 \mathrm{ng} / \mathrm{mL}$ in the Asian continent as a cut-off point for subsequent prostate biopsy. ${ }^{5,14}$ In Nigeria, Anunobi et al found that among patients with serum tPSA 4.0-49.9 ng/mL, core needle biopsy specimens revealed many benign prostates. ${ }^{15}$

Clinical adenocarcinoma of the prostate varies between races $^{16,17}$ and studies have shown that Africa has a high prevalence of the disease. ${ }^{1,18,19}$ It is important that malignancy is excluded in all cases of symptomatic prostatic enlargement, so this study aims to relate the histologic findings of all prostate specimens obtained from core needle biopsy, open simple prostatectomy, and transurethral resection of the prostate to the respective serum tPSA values in an attempt to decipher the role of serum tPSA in the clinician's decision-making.

\section{Materials and methods}

This was a hospital-based retrospective study from April 2009 to March 2012, ie, a period of 36 months. The case notes of patients who presented with and were evaluated for symptomatic prostate enlargement were retrieved and the relevant information contained therein was extracted for analysis. When biopsy was indicated, digitally guided transrectal extended sextant core needle biopsy of the prostate was offered due to the nonavailability of transrectal ultrasonography-guided biopsy. A disposable semiautomatic size $16 \mathrm{G}$ or $18 \mathrm{G}$ Trucut $^{\circledR}$ biopsy needle was used for each prostate biopsy. The indication for biopsy was a suspicious digital rectal examination (DRE) finding, suspicious prostate from abdominopelvic ultrasonography (USS), or elevated serum tPSA ( $>4 \mathrm{ng} / \mathrm{mL}$ ). In patients with a working diagnosis of benign prostatic hyperplasia (BPH) requiring surgical management, simple retropu-

Table I Age distribution of patients

\begin{tabular}{llll}
\hline $\begin{array}{l}\text { Age } \\
\text { (years) }\end{array}$ & Frequency $(\%)$ & $\begin{array}{l}\text { Mean tPSA } \\
(\mathbf{n g} / \mathbf{m L})\end{array}$ & $\mathbf{n}$ \\
\hline $40-49$ & $\mathrm{I}(7)$ & $0.50 \pm 0.00$ & $\mathrm{I}$ \\
$50-59$ & $12(9.0)$ & $7.76 \pm 7.37$ & $\mathrm{II}$ \\
$60-69$ & $54(40.3)$ & $18.95 \pm 24.35$ & 47 \\
$70-79$ & $43(32.1)$ & $30.71 \pm 33.65$ & 39 \\
$80-89$ & $22(16.4)$ & $31.87 \pm 29.90$ & 17 \\
$90-99$ & $2(1.5)$ & $66.70 \pm 47.09$ & 2 \\
Total & $134(100.0)$ & $24.35 \pm 29.13$ & $117(r=0.318, P<0.00 \mathrm{I})$ \\
\hline
\end{tabular}

Abbreviation: tPSA, total prostate-specific antigen.

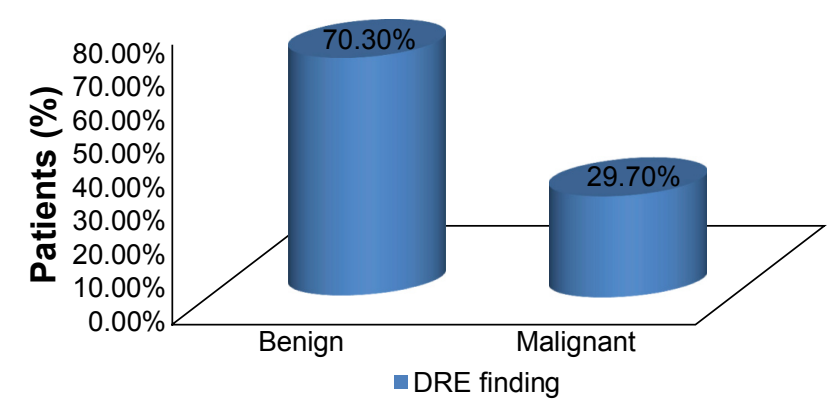

Figure I Findings on DRE.

Abbreviation: DRE, digital rectal examination.

bic prostatectomy, transvesical prostatectomy, or transurethral resection of the prostate was offered. All specimens were sent for histologic analysis by a pathologist.

The age and nationality of the patients were noted from the case notes. In addition, the DRE finding, serum tPSA result, USS assessment of the prostate, and the histologic report on the various specimens were extracted from each patient's case notes for analysis. The data analysis was done using Statistical Package for the Social Sciences version 20 software (IBM Corporation, Armonk, NY, USA). The Pearson correlation was used to test for association between numeric data. The chi-square test was used for nonparametric tests (Yates correction for continuity was employed when necessary). The level of significance was set at a two-tailed $P$-value of $<0.05$.

\section{Results}

Case notes for 134 patients were identified, with only 117 having documented tPSA. The number of patients in each age group and the average tPSA for the respective age groups are shown in Table 1.

\section{DRE findings}

DRE was documented for 128 patients. Findings were benign in $90(70.3 \%)$, and suspicious or suggestive of malignancy in 38 (29.7\%), as shown in Figure 1.

\section{Serum tPSA}

The result for serum tPSA was documented for 117 patients. The average value was $24.35 \pm 29.13 \mathrm{ng} / \mathrm{mL}$, with a range of $0.4-100 \mathrm{ng} / \mathrm{mL}$. As shown in Table $2,74.4 \%$ of tPSA values were $>4 \mathrm{ng} / \mathrm{mL}$ while $25.6 \%$ were $\leq 4 \mathrm{ng} / \mathrm{mL}$.

Table 2 Serum total prostate-specific antigen

\begin{tabular}{ll}
\hline Serum tPSA $(\mathbf{n g} / \mathbf{m L})$ & Frequency $(\%)$ \\
\hline$>4$ & $87(74.4)$ \\
$\leq 4$ & $30(25.6)$ \\
Total & $117(100.0)$ \\
\hline
\end{tabular}

Abbreviation: tPSA, total prostate-specific antigen. 


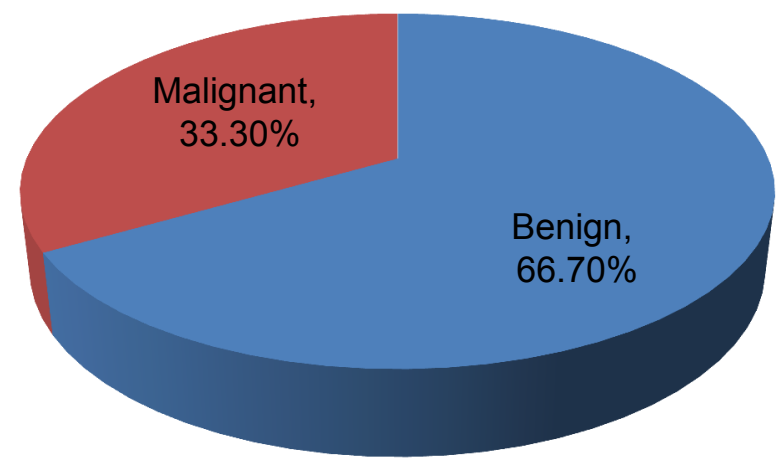

Figure 2 Abdominopelvic ultrasound scan findings.

\section{USS scanning}

USS was done in 110 patients, with the results presented in Figure 2. The findings were inconclusive in two patients. In the remaining 108 patients, findings were benign in 72 $(66.7 \%)$ and suspicious in $36(33.3 \%)$.

\section{Prostate biopsy}

Forty-six patients had histology results (Table 3). Adenocarcinoma was confirmed in $26(56.5 \%)$, while 19 (41.3\%) showed benign features. One patient (2.2\%) had high-grade prostatic intraepithelial neoplasia.

\section{Histology of prostatectomy specimens}

A total of 23 patients underwent prostatectomy over the study period; $19(82.6 \%)$ had open prostatectomy and four $(17.4 \%)$ had transurethral resection of the prostate. Seven of the 23 patients who had prostatectomy underwent prostate biopsy due to serum tPSA $>4 \mathrm{ng} / \mathrm{mL}$. The histology reports were BPH. Subsequent histology reports of prostatectomy specimens from these seven patients confirmed BPH in six and adenocarcinoma (Gleason score $2+3$ ) in one. Table 4 shows the histologic report of the 23 prostatectomy specimens: $18(78.3 \%)$ were nodular hyperplasia $(\mathrm{BPH})$, four $(17.4 \%)$ were chronic inflammatory cell infiltration on a background of nodular hyperplasia (BPH + prostatitis), and one (4.3\%) was adenocarcinoma (Gleason score 2+3).

\section{Summary of histology reports}

Thirty-nine patients underwent prostate biopsy due to suspicious prostates (suspicious DRE, suspicious ultrasound

Table 3 Histology on transrectal core needle prostate biopsy

\begin{tabular}{ll}
\hline Histology & Frequency (\%) \\
\hline Adenocarcinoma & $26(56.5)$ \\
Benign & $19(41.3)$ \\
High-grade PIN & $1(2.2)$ \\
Total & $46(100.0)$ \\
\hline
\end{tabular}

Abbreviation: PIN, prostatic intraepithelial neoplasia.
Table 4 Histology of prostatectomy specimens

\begin{tabular}{ll}
\hline Histology result & Frequency (\%) \\
\hline BPH & $18(78.3)$ \\
BPH + prostatitis & $4(17.4)$ \\
Adenocarcinoma & $1(4.3)$ \\
Total & $23(100.0)$ \\
\hline
\end{tabular}

Abbreviation: $\mathrm{BPH}$, benign prostatic hyperplasia.

findings, or tPSA $>4 \mathrm{ng} / \mathrm{mL}$ ), while 16 patients had simple prostatectomy without prior biopsy since there was no indication for biopsy, giving a total of 55 patients. Of the 39 prostates that were biopsied, 26 were adenocarcinoma, one was highgrade prostatic intraepithelial neoplasia, and 12 were benign. Seven of the 12 cases that were benign underwent prostatectomy. Thus, seven patients had prostate biopsy initially and prostatectomy at a later date, resulting in 62 histologic reports that were analyzed (Figure 3). The histologic reports on all the prostate specimens were categorized for patient age, DRE findings, serum tPSA values, and USS reports (Table 5).

There were nine histologic reports for patients with serum tPSA $>4 \mathrm{ng} / \mathrm{mL}$ and $10 \mathrm{ng} / \mathrm{mL}$. The DRE findings, USS findings, and duration of follow-up for these patients were analyzed (Table 6). Four with benign DRE and USS findings had benign histology, while three adenocarcinoma cases had either suspicious DRE or USS findings.

\section{Discussion}

Case notes for 134 patients seen within the study period could be retrieved for analysis. All were for Nigerians of mean age $69.97 \pm 9.50$ (45-94) years with a modal range of 60-69 years (Table 1). They all had symptomatic enlargement of the prostate. One hundred and twenty-eight DREs of the prostate were performed, with 90 (70.3\%) and 38 (29.7\%) feeling benign and malignant, respectively (Figure 1). Twenty-four (85.7\%) of the 28 prostates that were histologically confirmed as

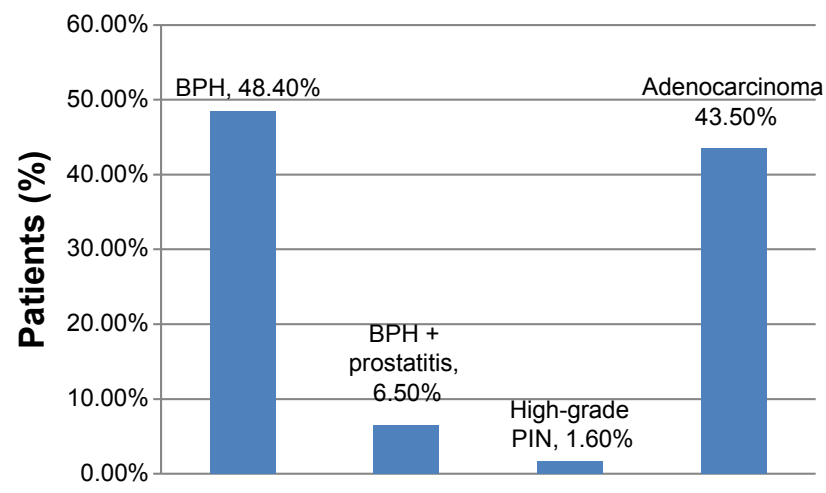

Figure 3 Summary of histology.

Abbreviations: BPH, benign prostatic hyperplasia; PIN, prostatic intraepithelial neoplasia. 
Table 5 Relationship between age, DRE, serum tPSA, USS, and histology

\begin{tabular}{|c|c|c|c|c|}
\hline & \multicolumn{2}{|l|}{ Histology } & \multirow[t]{2}{*}{$\chi_{\text {Yates }}^{2}$} & \multirow[t]{2}{*}{$P$-value } \\
\hline & Benign $(n=34)$ & Malignant $(n=28)$ & & \\
\hline${ }^{\mathrm{a} A g e} \geq 65$ years & $24(70.6 \%)$ & 27 (96.4\%) & 5.366 & $0.02 I^{*}$ \\
\hline aSuspicious DRE findings & $4(\mathrm{II} .8 \%)$ & 24 (85.7\%) & 5.319 & $0.000 *$ \\
\hline bSerum tPSA ( $>4 \mathrm{ng} / \mathrm{mL})$ & $27(81.8 \%)$ & $26(96.3 \%)$ & 1.779 & 0.182 \\
\hline${ }^{\mathrm{b}}$ Serum tPSA ( $\left.>10 \mathrm{ng} / \mathrm{mL}\right)$ & $22(66.7 \%)$ & 25 (92.6\%) & 4.453 & $0.035^{*}$ \\
\hline 'Suspicious USS findings & $10(30.3 \%)$ & $18(69.2 \%)$ & 7.345 & $0.007^{*}$ \\
\hline
\end{tabular}

Notes: $* P<0.05$ is significant. ${ }^{a} n=62$ ( 34 benign cases, 28 malignant cases); ${ }^{b} n=60$ ( 33 benign cases, 27 malignant cases); ${ }^{c} n=59$ ( 33 benign cases, 26 malignant cases).

Abbreviations: DRE, digital rectal examination; USS, abdominopelvic ultrasonography; tPSA, total prostate-specific antigen.

adenocarcinoma of the prostate were suspicious or malignant on DRE (Table 5). A similar result was obtained by Badmus et $\mathrm{al}^{1}$ in Nigeria (92.1\%), but not by Ma and $\mathrm{Wan}^{20}$ in the People's Republic of China (31.25\%) or Palmerola et $\mathrm{al}^{21}$ in the USA (44\%). In contrast, of the 34 benign histology reports, four (11.8\%) had suspicious DRE findings. The high sensitivity (85.7\%), specificity (88.2\%), positive predictive value $(85.7 \%)$, and negative predictive value $(88.2 \%)$ of DRE in this analysis (Table 7) may be due to late presentation, by which time locoregional features of the disease were well established.

USS assessment was documented conclusively for 108 prostates, with $72(66.7 \%)$ showing benign features and $36(33.3 \%)$ showing malignant features (Figure 2). Table 5 shows that 18 of the 28 malignant prostates $(69.2 \%)$ had a suspicious ultrasonography report. In Southwestern Nigeria, Badmus et $\mathrm{al}^{1}$ obtained a value of $78.8 \%$. In contrast, of the 34 histologically benign prostates, ten $(30.3 \%)$ were reported as suspicious for malignancy by ultrasonography.

A total of 117 tPSA values were documented. There was a significant positive correlation between age and serum tPSA $(r=0.318, P<0.001$; Table 1$)$. A similar correlation was documented by Mochtar et al for patients with a symptomatic benign prostate. ${ }^{22}$ tPSA values ranged from 0.4 to $100 \mathrm{ng} / \mathrm{mL}$, with a mean of $24.35 \pm 29.13 \mathrm{ng} / \mathrm{mL}$ and a median of $12.7 \mathrm{ng} / \mathrm{mL}$. Eighty-seven of these 117

Table 6 Features of prostates with tPSA $>4 \mathrm{ng} / \mathrm{mL}$ to $10 \mathrm{ng} / \mathrm{mL}$

\begin{tabular}{lllll}
\hline Histology & DRE & USS & tPSA & $\begin{array}{l}\text { Follow-up } \\
\text { (months) }\end{array}$ \\
\hline BPH & Benign & Suspicious & 4.5 & 16 \\
BPH & Benign & Benign & 4.8 & 30 \\
Adenocarcinoma & Benign & Suspicious & 5.2 & 12 \\
BPH & Benign & Suspicious & 6.4 & 12 \\
Adenocarcinoma & Suspicious & Benign & 7 & 4 \\
BPH & Benign & Benign & 7 & 34 \\
BPH & Benign & Benign & 7 & 36 \\
Adenocarcinoma & Suspicious & Suspicious & 8.3 & 4 \\
\hline
\end{tabular}

Abbreviations: BPH, benign prostatic hyperplasia; DRE, digital rectal examination; USS, abdominopelvic ultrasonography; tPSA, total prostate-specific antigen.
tPSA values $(74.4 \%)$ were $>4 \mathrm{ng} / \mathrm{mL}$ and $30(25.6 \%)$ were $\leq 4 \mathrm{ng} / \mathrm{mL}$ (Table 2). Applying a serum tPSA of $>4 \mathrm{ng} / \mathrm{mL}$, the sensitivity and specificity of tPSA for detecting prostate cancer were $96.3 \%$ and $18.2 \%$, respectively, with a negative predictive value of $85.7 \%$. These were similar to the findings of Lokuhetty et al. ${ }^{9}$ Therefore, in this study, using a serum tPSA $>4 \mathrm{ng} / \mathrm{mL}$ alone, $81.8 \%$ of benign prostates would have been subjected to unnecessary transrectal biopsy. However, applying a serum tPSA of $>10 \mathrm{ng} / \mathrm{mL}$ alone, with a sensitivity of $85.2 \%$ and a specificity of $33.3 \%$, the negative predictive value decreased to $73.3 \%$. Similarly, from the study by Abbiyesuku et $\mathrm{a}^{23}$ only $37 \%$ and $54.3 \%$ of histologically benign prostatic enlargements had tPSA $<4 \mu \mathrm{g} / \mathrm{L}$ and $<10 \mu \mathrm{g} / \mathrm{L}$, respectively. Thompson et a $1^{13}$ concluded that there is no cutpoint of PSA with simultaneous high sensitivity and high specificity for monitoring healthy men for prostate cancer, but rather a continuum of prostate cancer risk at all PSA values. The inference from the review by Schröder and Roobol ${ }^{24}$ is similar to the conclusion of Thompson et al. In our study of men with symptomatic prostatic enlargement, serum tPSA values also form a continuum with increasing risk of prostate cancer. It may be argued that it is necessary to have followed-up the patients with tPSA $>4 \mathrm{ng} / \mathrm{mL}$, but benign histological report, for longer periods to ensure they do not turn out to be cases of false negative histological reports. However, de-novo prostate cancer can also occur in the residual prostates after simple prostatectomy for benign prostate enlargement.

Table 7 Sensitivity parameters

\begin{tabular}{llllllllll}
\hline Test & $\mathbf{n}$ & TP & TN & FP & FN & Sensitivity & Specificity & PPV & NPV \\
\hline DRE & 62 & 24 & 30 & 4 & 4 & $85.7 \%$ & $88.2 \%$ & $85.7 \%$ & $88.2 \%$ \\
PSA $>4$ & 60 & 26 & 6 & 27 & 1 & $96.3 \%$ & $18.2 \%$ & $49.1 \%$ & $85.7 \%$ \\
PSA $>10$ & 60 & 23 & 11 & 22 & 4 & $85.2 \%$ & $33.3 \%$ & $51.1 \%$ & $73.3 \%$ \\
USS & 60 & 19 & 23 & 10 & 8 & $70.4 \%$ & $69.7 \%$ & $65.5 \%$ & $74.2 \%$ \\
\hline
\end{tabular}

Abbreviations: TP, true positive; TN, true negative; $F P$, false positive; $F N$, false negative; PPV, positive predictive value; NPV, negative predictive value; DRE, digital rectal examination; PSA, prostate-specific antigen; USS, abdominopelvic ultrasonography. 


\section{Conclusion}

Among Nigerian men with symptomatic prostate enlargement, serum tPSA $>4 \mathrm{ng} / \mathrm{mL}$ and $10 \mathrm{ng} / \mathrm{mL}$ may not be interpreted in isolation as an indication for prostate biopsy, since from this analysis $81.8 \%$ of benign prostate specimens had values $>4 \mathrm{ng} / \mathrm{mL}$. However, with a negative predictive value of $85.7 \%$ for serum tPSA $>4 \mathrm{ng} / \mathrm{mL}$ (Table 7 ), symptomatic patients with $\mathrm{tPSA} \leq 4 \mathrm{ng} / \mathrm{mL}$ could be safely managed as benign prostate enlargement in the absence of suspicious DRE and USS findings. Applying serum tPSA $>10 \mathrm{ng} / \mathrm{mL}$ in isolation as a cut-off may appear to have reduced the number of benign prostates that would have been biopsied by $15.1 \%$, but also increased the missed malignant prostates by $3.6 \%$. The sensitivity of DRE and USS in detecting suspicious features in symptomatic prostate enlargement should not be overlooked, especially in our community, where patients directly bear the cost of medical treatment. Serum tPSA should be considered as an invaluable component of the triad (DRE, ultrasonography, PSA) in the management of patients with symptomatic prostate enlargement. DRE and ultrasonography findings are important in deciding which prostate to biopsy when serum tPSA is between $4 \mathrm{ng} / \mathrm{mL}$ and $10 \mathrm{ng} / \mathrm{mL}$ (Table 6).

\section{Disclosure}

The authors report no conflicts of interest in this work.

\section{References}

1. Badmus TA, Adesunkanmi AK, Yusuf BM, et al. Burden of prostate cancer in Southwestern Nigeria. Urology. 2010;76(2):412-416.

2. National Institute of Clinical Excellence. Prostate cancer diagnosis and treatment. Available from: http://www.nice.org.uk/nicemedia/pdf/ CG58FullGuideline.pdf. Accessed November 24, 2014.

3. Bensalah K, Lotan Y, Karam JA, Shariat SF. New circulating biomarkers for prostate cancer. Prostate Cancer Prostatic Dis. 2008;11(2):112-120.

4. Wallner LP, Morgenstern H, McGree ME, et al. The effects of body mass index on changes in prostate-specific antigen levels and prostate volume over 15 years of follow-up: implications for prostate cancer detection. Cancer Epidemiol Biomarkers Prev. 2011;20(3):501-508.

5. Lee SE, Hong SK, Park HZ, et al. Higher body mass index is associated with lower risk of prostate cancer detection via multi $(\geq 12)$-core prostate biopsy in Korean men. Urology. 2010;76(5):1063-1066.

6. Moussa AS, Li J, Soriano M, Klein EA, Dong F, Jones JS. Prostate biopsy clinical and pathological variables that predict significant grading changes in patients with intermediate and high grade prostate cancer. BJU Int. 2009;103(1):43-48.
7. Pepe $P$, Aragona F. Incidence of insignificant prostate cancer using free/total PSA: results of a case-finding protocol on 14,453 patients. Prostate Cancer Prostatic Dis. 2010;13(4):316-319.

8. Tubaro A, De Nunzio C, Mariani S, et al. Reduction of prostatespecific antigen after tamsulosin treatment in patients with elevated prostate-specific antigen and lower urinary tract symptoms associated with low incidence of prostate cancer at biopsy. Urology. 2010;76(2): 436-441.

9. Lokuhetty MD, Wijesinghe HD, Abeysuriya DT, Samarasinghe UC, Perera ND. Transrectal ultrasound guided prostate biopsies: a single centre experience in Sri Lanka. Ceylon Med J. 2009;54(1):6-9.

10. Ajape AA, Ibrahim KO, Fakeye JA, Abiola OO. An overview of cancer of the prostate diagnosis and management in Nigeria: the experience in a Nigerian tertiary hospital. Ann Afr Med. 2010;9(3):113-117.

11. Catalona WJ, Smith DS, Ratliff TL, et al. Measurement of prostatespecific antigen in serum as a screening test for prostate cancer. $N \mathrm{Engl}$ J Med. 1991;324(17):1156-1161.

12. Catalona WJ, Smith DS, Ornstein DK. Prostate cancer detection in men with serum PSA concentrations of $2.6-4.0 \mathrm{ng} / \mathrm{mL}$ and benign prostate examination. Enhancement of specificity with free PSA measurements. JAMA. 1997;277(18):1452-1455.

13. Thompson IM, Ankerst DP, Chi C, et al. Operating characteristics of prostate-specific antigen in men with an initial PSA level of $3.0 \mathrm{ng} / \mathrm{mL}$ or lower. JAMA. 2005;294(1):66-70.

14. Hong SK, Oh JJ, Byun S, et al. Impact of diabetes mellitus on the detection of prostate cancer via contemporary multi $(\geq 12)$-core prostate biopsy. Prostate. 2012;72(1):51-57.

15. Anunobi CC, Akinde OR, Elesha SO, Daramola AO, Tijani KH, Ojewola RW. Prostate diseases in Lagos, Nigeria: a histologic study with tPSA correlation. Niger Postgrad Med J. 2011;18(2):98-104.

16. Mettlin CJ, Murphy G. The national cancer base report on prostate cancer. Cancer. 1994;74(5):1640-1648.

17. Bowa K. An overview of the diagnosis and management of prostate cancer in Nigeria: experience from a north-central state of Nigeria. Ann Afr Med. 2010;9(3):111-112.

18. Osegbe DN. Prostate cancer in Nigerians: facts and nonfacts. J Urol. 1997;157(4):1340-1343.

19. Bowa K, Kachimba JS, Labib M, Mudenda V, Chikwenya M. The changing pattern of urological cancers in Zambia. Med J Zambia. 2009;35(4):157-159.

20. Ma H, Wan B. [Relationship of the positive rate of TRUS guided prostate biopsies with routine diagnostic findings in detecting prostate cancer]. Zhonghua Nan Ke Zue. 2013;19(1):40-43. Chinese.

21. Palmerola R, Smith $P$, Elliot V, et al. The digital rectal examination (DRE) remains important - outcomes from a contemporary cohort of men undergoing an initial $12-18$ core prostate needle biopsy. Can J Urol. 2012;19(6):6542-6547.

22. Mochtar CA, Kiemeney LA, van Riemsdijk MM, et al. Prostatespecific antigen as an estimator of prostate volume in the management of patients with symptomatic benign prostatic hyperplasia. Eur Urol. 2003;44(6):695-700.

23. Abbiyesuku FM, Shittu OB, Oduwole OO, Osotimehin BO. Prostate specific antigen in the Nigerian African. Afr J Med Med Sci. 2000;29(2):97-100.

24. Schröder FH, Roobol MJ. Defining the optimal prostate-specific antigen threshold for the diagnosis of prostate cancer. Curr Opin Urol. 2009;19(3):227-231.
Clinical Interventions in Aging

\section{Publish your work in this journal}

Clinical Interventions in Aging is an international, peer-reviewed journal focusing on evidence-based reports on the value or lack thereof of treatments intended to prevent or delay the onset of maladaptive correlates of aging in human beings. This journal is indexed on PubMed Central, MedLine,

\section{Dovepress}

CAS, Scopus and the Elsevier Bibliographic databases. The manuscript management system is completely online and includes a very quick and fair peer-review system, which is all easy to use. Visit http://www.dovepress. com/testimonials.php to read real quotes from published authors. 